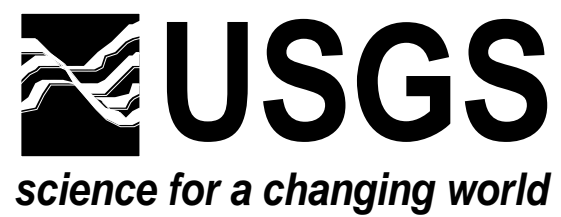

\title{
A Rapid Array Mobilization Procedure (RAMP) Agreement for the Central United States
}

By Paul Bodin, Gary Pavlis, Eugene Schweig, and Joan Gomberg

This report is preliminary and has not been reviewed for conformity with U.S. Geological Survey editorial standards or with the North American Stratigraphic Code.

Any use of trade, firm, or product names is for descriptive purposes only and does not imply endorsement by the U.S. Government.

\section{Open-File Report 03-015}

U.S. Department of Interior

U.S Geological Survey 


\section{Table of Contents}

I. Summary 1

II. Need for a Central U.S. RAMP 2

III. Objectives 5

A. General Objectives 5

B. Scientific Goals Under Different Earthquake Scenarios 7

1. Moderate,Significant Earthquake Somewhere in the Central U.S. 7

2. Major Earthquake within the Central U.S. 9

IV. Activation 11

V. Field Operations

A. Instrumentation and Resources 12

$\begin{array}{ll}\text { B. Personnel } & 14\end{array}$

$\begin{array}{ll}\text { C. Communications } & 14\end{array}$

$\begin{array}{ll}\text { D. Transportation } & 15\end{array}$

$\begin{array}{ll}\text { E. Logistics } & 15\end{array}$

$\begin{array}{ll}\text { F. Coordination } & 16\end{array}$

VI. Post-RAMP Data Handling Procedures 16

$\begin{array}{ll}\text { A. Data Collection and Quality } & 17\end{array}$

B. Data Assembly and Documentation $\quad 17$

$\begin{array}{ll}\text { C. Distribution and Archive } & 18\end{array}$

VII. Training and Long-term Continuation of a RAMP Plan 19

$\begin{array}{ll}\text { References } & 21\end{array}$

Appendix A. Participants in the 1995 Workshop 21 


\section{Summary}

Thirty-five participants representing 10 universities and 8 governmental organizations met at a workshop in Memphis, Tennessee, on January 28-29, 1995 (see Appendix A). The participants agreed to cooperate in seismological aftershock studies of future moderate and large earthquakes in the Central United States (CUS). Since 1995 much has changed technologically and organizationally, particularly with regards to the birth of the Advanced National Seismic System (ANSS). The ANSS has lead to a new, heightened level of cooperation and integration among seismic monitoring networks in the Central U.S. Technological advances in communications and in recording capabilities, and reduction in the cost of seismographic instrumentation also have been significant since 1995. Finally, efforts to coordinate post-earthquake response at the national, regional and local levels and among scientists, engineers, emergency response agencies, public agencies, and the media have resulted in new, coordinated response planning activities. In particular, a national-level National Earthquake Hazards Reduction Program (NEHRP) Post-earthquake Investigations Plan has been adopted by NEHRP agencies and the Earthquake Engineering Research Institute (EERI), which is linked to a new plan for the operations of CUS Post-earthquake Technical Clearing House developed under the auspices of the Central U.S. Earthquake Consortium (CUSEC) and the Association of CUSEC State Geologists.

This plan seeks to ensure the most rapid and effective seismological response, as a component of the regional and national response plans and the ANSS, and is known as a Rapid Array Mobilization Procedure (RAMP). In this context, the RAMP plan provides detailed guidance to one scientific aspect of earthquake response. This report summarizes the results of the 1995 workshop that focused on the scientific issues relevant to the Central U.S. Details of the structure of the cooperation among participants will be covered herein as well. Earthquake response is one function of the ANSS and as such, a standing postearthquake response subcommittee of the ANSS-MA (Mid-America region of the ANSS) 
should be formed to oversee the maintenance and implementation of this plan. Its members need not all be members of the ANSS-MA regional advisory committee, but at least one shall be and will be responsible for reporting to the advisory committee. A database of likely aftershock study participants and resources will be made available as part of the ANSS-MA on-line database at http://www.anss-ma.org/.

This document addresses the following:

(1) The need for an earthquake response component of the ANSS-MA

(2) The scientific goals of future temporary seismographic deployments,

(3) The current status of available seismographic instrumentation within the region,

(4) Guidelines for the implementation of studies,

(5) Post-experiment data handling procedures, and

(6) Strategies for keeping this plan elastic and strong.

A RAMP will be implemented if the criteria outlined in the NEHRP Post-earthquake Investigations Plan are met; these require that an earthquake a) results in a Presidential disaster declaration or b) be declared worthy of response by a NEHRP agency. For earthquakes that don't meet these criteria, a RAMP still may be invoked but in this case procedures covered in the NEHRP and CUSEC plans may be implemented on an ad hoc basis, depending on the needs and capabilities of the RAMP participants.

\section{Need for a Central U.S. RAMP}

The Central U.S. (CUS) is threatened by earthquakes within the New Madrid seismic zone, the Wabash Valley seismic zone, the Appalachian seismic zone, along the Grenville front, and other seismogenic areas in the region (Figure 1). While the earthquake potential of the New Madrid seismic zone is a matter of historical record, geological and paleoseismic investigations have pointed to these other source areas in the region as having the potential to cause damaging earthquakes. The historical and instrumental seismic 
records indicate that the potential exists for a moderate, but damaging, earthquake anywhere, even outside of these seismic zones.

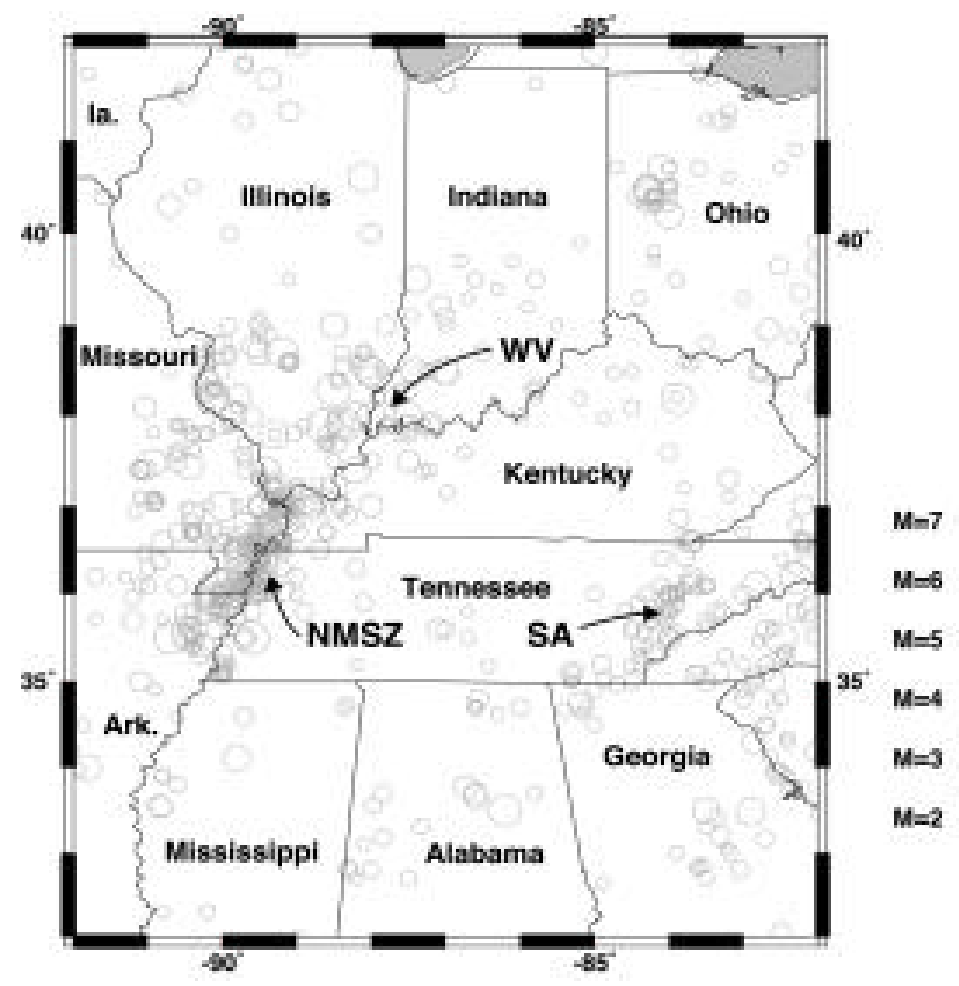

A CUS Rapid Array Mobilization Procedure (RAMP) provides the framework for effective efficient deployment of portable seismographic instrumentation, and for timely analysis and dissemination of resulting data. Most importantly, a RAMP facilitates the seismologic response to moderate or large earthquakes in the CUS. A RAMP also facilitates planned short-term seismologic field experiments, often conducted in response to unforeseen experimental opportunities. Both types of responses yield information that serves as critical input to scientific seismic hazard assessment studies, to design of seismically engineered structures, and to long-term mitigation efforts.

A RAMP is especially necessary in a region like the CUS, which includes the states of Tennessee, Arkansas, Missouri, Illinois, Indiana, Kentucky, Ohio, and Mississippi, and surrounding states where appropriate. The CUS differs from more tectonically active regions in that the Earth's surface reveals few clues about the location of faults, characteristics of previous ruptures, and the response of the ground to seismic deformation. 
To the extent that the past provides keys to the future, uncertainty about the earthquake history of the CUS region challenges our ability to anticipate the hazard from future earthquake events. Also, unlike more tectonically active regions with more frequent earthquakes, the CUS has had few opportunities to learn directly from moderate to large earthquakes. A RAMP will enable us to maximize such opportunities when they do occur. While a significant seismic hazard clearly exists in the CUS, a relatively low occurrence rate of significant earthquakes has led to the operation of relatively few permanent seismic stations. (A list and map of these will be available on the ANSS-MA website at http://www.anss-ma.org/.) Thus, when a significant earthquake happens in the CUS, we may not be able to collect data critical to constraining the fundamental characteristics (e.g., accurate location, causative faults) provided by mainshock recordings at near distances. Because aftershock data provide important constraints on these characteristics, such data must be collected and analyzed as rapidly as possible. A possibly short duration of aftershock sequences following moderate CUS earthquakes also necessitates rapid response. One purpose of a RAMP is to ensure that the response is rapid.

A RAMP provides a framework for how resources may be shared in order to maximize the yield and utility of valuable data. The geographic and political diversity of the fourteen states comprising the CUS present significant logistical challenges to coordinating responses to hazards that do not respect state or institutional boundaries. CUS diversity also applies to communications within the region; information is transmitted through widely varied means to many institutions. A RAMP facilitates the complex networking required for an effective earthquake response. This networking extends beyond the seismologic community, to those concerned with aspects of post-earthquake recovery and, ultimately, with long-term planning.

As discussed in more detail below, the current regional seismograph network coverage is inadequate to ensure precise estimation of aftershock focal parameters. Moreover, there may be large uncertainties in source parameters of moderate mainshocks should they not 
occur within the few well-instrumented portions of the region. It is also likely that scientifically important earthquakes will occur on the periphery of such regions, or in ones that are poorly instrumented. In addition to the possibility of using aftershocks to study propagation and engineering questions, aftershock studies in this region provide the basic seismological data to reveal mainshock focal parameters, rupture dimensions, and so forth.

\section{Objectives}

\section{A. General Objectives}

The appropriate scientific response to a significant earthquake in the CUS is driven by one overriding issue — the regional distribution of permanent seismographic network stations. At this time, the vast majority of the CUS is sparsely instrumented with seismographs. The exception is the heart of the New Madrid seismic zone, which is monitored by Cooperative New Madrid Seismic Network (CNMSN), operated by The University of Memphis and Saint Louis University (see http://folkworm.ceri.memphis.edu/). On the other hand, the ANSS-MA ultimately will provide outstanding monitoring capabilities at regional distances for the entire region (see http://www.anss-ma.org/). With modern waveform inversion techniques, we expect it will be possible to determine accurate source parameters routinely for any event larger than about M 3.5 to M 4 .

There are two significant consequences of the present state of seismic network capabilities in this area.

(i) A large fraction of significant earthquakes are likely to occur in an area with poor seismic station coverage.

(ii) Most aftershocks of significant earthquakes will not even be recorded, and few will have any well-constrained estimates of their source parameters.

These facts have a controlling influence on the scientific objectives of any RAMP deployment in the CUS. In particular, it was universally recognized by participants in the 
RAMP workshop held in January, 1995, that the highest scientific priority for most RAMP deployments will be simply to field a temporary network designed to retrieve reliable source parameters of aftershocks. That is, in most cases seismic stations would be deployed in a relatively uniform distribution near the aftershock zone. Data from these stations would be used with conventional seismological analysis procedures to produce estimates of aftershock source parameters: epicentral location, depth, focal mechanism, and magnitude. Furthermore, for larger aftershocks, the use of modern high dynamic range instruments in the near-field, in combination with regional stations will provide important scientific returns, such as imaging more complex source phenomena (e.g., irregularities in slip along a fault surface or directivity effects) or quantifying site response.

The retrieval of source parameters of major earthquakes is important for addressing these major scientific issues related to any earthquake in this region:

(i) What are the geologic structures with which the earthquake was associated, and what is the geometry of the fault system that produced the earthquake?

In the CUS, our knowledge of the structures capable of producing major earthquakes is very limited. Accumulating knowledge on the nature of these structures is important for understanding the long-term earthquake hazards in the region.

(ii) What is the stress drop of a mainshock and its aftershocks?

There is a longstanding debate about whether the stress drops of infrequent, intracontinental earthquakes are much higher (and hence occur on much smaller faults) than earthquakes of similar magnitude in a tectonically active region like California. If so, it has a tremendous impact on appraising the hazard imposed by any potentially active fault in the region. High quality data provided by RAMP deployments following a significant earthquake will provide some of the basic data required to answer this question. 
(iii) After a large earthquake, how is the aftershock sequence evolving? Is it a mainshock-aftershock sequence, or is the earthquake that just happened a foreshock?

This is a very important issue for intracontinental earthquakes. The only major earthquake that have occurred historically in the region (the New Madrid earthquakes of 1811-1812) were not a single large earthquake but a sequence of at least three major earthquakes. Paleoseismological studies in the New Madrid region (e.g., Tuttle et al., 2002) suggest that sequences may be characteristic of large earthquakes in the region. Thus, in the event of a major Central U.S. earthquake, defining the temporal evolution of the sequence will be very important information to provide the public to either assure them that the sequence is probably dying down or to warn them that a potentially larger event could be on the way.

(iv) Was this earthquake induced?

It has been proposed that some moderate earthquakes in the Central and Eastern U.S. have been induced by impoundment of reservoirs or from fluid injection in wells. Such hypotheses cannot be tested without accurate estimates of aftershock source parameters.

\section{B. Scientific Goals Under Different Earthquake Scenarios}

1. Moderate, significant earthquake somewhere in the Central U.S.

It is expected that the general objectives listed above will define the principal research effort for the majority of earthquakes that are likely to occur within the CUS. The reason for this is that by far the most likely scenario we will face is a moderate earthquake (M 4.5 to M 5.5). Experience has shown that an earthquake of this size will be widely felt, but would probably cause little, if any, loss of life and relatively modest property damage compared to recent much larger California earthquakes such as the Loma Prieta or the 
Northridge earthquakes. On the other hand, such an event would be significant scientifically within the region, and in most cases would be worthy of study. To clarify this we consider two end member situations, and then simply state that all other examples are somewhere in between.

(i) A magnitude 4.5 earthquake occurs near the center of the New Madrid seismic zone. Because the network coverage should be adequate for most scientific needs, some of the auxiliary experiments noted below for larger events might be appropriate.

(ii) A magnitude 5+ event well outside the New Madrid seismic zone, but within the CUS region would almost certainly justify a RAMP deployment. Any such event is a rare occurrence that could be, literally, a once in a lifetime opportunity. The focus of a RAMP for an event of this type would almost certainly be estimation of source parameters. Experience has shown that aftershock sequences following regional events of this size tend to have very short durations. Thus, experiments that depend upon deployments that could not be fielded within a few days of the mainshock would, in most cases, be not worthwhile.

For events not deemed significant according to the NEHRP Plan criteria, the decision to invoke a RAMP will, without doubt, most likely depend on two basic issues:

(i) Is anyone interested in fielding equipment to conduct such an exercise?

(ii) Can these people sequester promises for funds to support the effort on short notice?

In most cases with events of this size the most prominent secondary experimental objective will be deployment of quality digital instruments at existing strong-motion stations. The use of empirical Green's functions derived from aftershock deployments to deconvolve strong-motion records from a mainshock is a well-established technique. Given the wide spacing of strong-motion instruments in the region, the number of 
candidate stations that might be useful in this type of analysis is probably small. Therefore, we anticipate that this type of experiment could often be integrated into the aftershock network deployed to determine aftershock source parameters. It should therefore be standard practice that any free field strong-motion accelerograph within $50 \mathrm{~km}$ of the mainshock be a prime candidate for use as a broadband, high-dynamic range, digital 3component, aftershock network station. The potential gain in knowledge, and the ease of carrying this out offsets concerns that the utility of the empirical Green's function technique for events of this magnitude range are still debatable.

\section{Major earthquake within the central U.S.}

For seismological response purposes in the CUS an earthquake of magnitude 5.5 or larger can probably safely be defined as "major". There have been no earthquakes of this magnitude in the past century and only 2 since the 1811-1812 New Madrid earthquake sequence, so by any reasonable measure an event of this size is rare. Furthermore, the likelihood of significant damage and loss of life begins to become important for such events. The key issue following a major earthquake will not be if there will be a RAMP response, but rather how it will be organized. The 1995 workshop participants recognized that, for major earthquakes, as the size of the event increases, the complexity of organizing the field effort will undoubtedly increase.

Three factors drastically change the rules for larger earthquakes within this scenario:

(i) The number of potential participants increases with the size of the mainshock.

(ii) Many of the new players are likely to have their own instruments. Furthermore, it is a stated IRIS-PASSCAL policy that in the event of a "major" earthquake instruments can be recalled from other experiments. Thus, the pool of quality instruments that might be available is also likely to increase with source size. 
(iii) Rapid deployment becomes less important as mainshock magnitude increases because aftershocks are likely to occur at significant rates for much longer time periods after the mainshock.

As a result of these factors, the range of potential experiments that could be conceived of and executed expands dramatically. The organizational model discussed below would sort out priorities for competing experiments by requiring each group in the RAMP deployment to negotiate with the Principal Investigator Team to stage a particular type of experiment.

Examples of experiments that were considered by participants include:

- Small-aperture-array experiments designed to study sources and wave propagation.

- Experiments with broadband sensors to study large scale basin response.

- Crustal structure experiments.

Aftershocks provide an active source area that could be used to estimate crustal structure using 3-D tomographic methods. Alternatively, one could deploy stations in linear profiles directed radially away from the source area to determine crustal structure using a modified refraction analysis. Both of these techniques have yielded valuable results from aftershocks of recent large events in California.

- $\quad$ Site response studies.

Site response studies are especially critical for any earthquake happening near a major urban area. However, similar studies are equally important for earthquakes that happen in more remote areas as they may, in some cases, provide analogs to near surface conditions at nearby urban areas that could be at risk. For example, site response studies of moderate earthquakes occurring under the thick sedimentary sequences of the New Madrid seismic zone are highly relevant for hazard mitigation in the city of Memphis because near-surface site conditions there may be similar. 
- Liquefaction and nonlinear soil response experiments.

Liquefaction and nonlinear soil response cannot be studied without the strong shaking provided by larger earthquakes. The aftershocks of any major earthquake provide important natural laboratories to study these phenomena.

\section{Activation}

A RAMP may be invoked for earthquakes that do not satisfy the NEHRP Post-earthquake Investigations Plan criteria. In these cases, the procedures described below may be invoked on an ad hoc basis depending on the particulars of the earthquake, participants, etc.

(i) All scientists interested in participating in an activated RAMP will assemble at the Post-earthquake Technical Clearing House designated as part of the NEHRP Post-earthquake Investigations Plan as soon as possible. A RAMP Coordinator and a Data Coordinator will be selected by RAMP participants and in consultation with the NEHRP Investigations Coordinator. Plans will be drawn up for immediate instrument deployment based on available instruments and experimental requirements. The RAMP Coordinator will assume responsibility for the deployment, and all coordination with the NEHRP Investigations Coordinator, the ANSS-MA regional advisory committee, and IRIS. The Data Coordinator will oversee data quality control and assembly of the final data product (see Section VI).

(ii) The RAMP Coordinator, or his/her designate, will act as the initial link to IRIS regarding the immediate availability of PASSCAL instruments, and the details of the mobilization. These details include: who is to be in charge of the deployment, how many instruments to ship, and where to ship them.

(iii) In the event that a RAMP is activated before a Post-earthquake Technical Clearing House has been designated, a provisional RAMP Coordinator and a 
Data Coordinator will be selected by RAMP participants. The composition of the participant group will depend on the location and magnitude of the earthquake, availability of personnel, etc., particularly for moderate and smaller events. The RAMP Coordinator will be responsible for seeing that RAMP activities are coordinated in whatever manner is most expedient, consistent with RAMP objectives, and allow for integration with the Post-earthquake Technical

Clearing House once established. He/she will also be responsible for the latter once feasible.

\section{Field Operations}

This section discusses the field operations of a CUS RAMP deployment. We assume that, at this point, decisions related to the scope and scientific objectives of a RAMP deployment and initial funding commitments have been made. Because time is a critical factor related to RAMP deployment objectives, we emphasize aspects of the field operations plans, particularly pre-arrangement plans, which will enhance rapid as well as effective deployment.

\section{A. Instrumentation and Resources}

Three main types of seismographs are likely to be used in CUS RAMP deployments: short-period analog, short-period digital, and broadband digital instruments. Short-period analog seismographs have the advantages of rapid deployment and a visual record, which can be used for immediate determination of the level of earthquake activity and determination of preliminary event locations. For these reasons, short-period analog seismographs should be used in initial stages of a RAMP deployment. However, analog instruments will be of more limited use in post-experiment data analysis and interpretation. Additionally, available analog instruments are mostly single component (usually vertical component), which limits their effectiveness in recording shear wave phases. Short-period 
digital seismographs will likely be the most useful instrument for CUS RAMP deployments because they can be rapidly deployed and provide digital records for subsequent data analysis and interpretation. The short-period digital seismographs are mostly multichannel instruments that have the advantage of providing 3-component seismic data that can be used to analyze and interpret all seismic phases. Furthermore, a large number (ten, initially from IRIS/PASSCAL; additional from both IRIS/PASSCAL and University and government sources) of reasonably matched, digital seismographs are available on short notice for RAMP deployments. Broadband digital seismographs can be used for a CUS RAMP deployment and could provide scientifically interesting data. However, effective deployment of broadband seismometers is more complicated and takes more time than short-period seismometer deployment. Furthermore, broadband seismometers deployed in the relatively unconsolidated surficial materials that characterize much of the seismically active CUS may be unstable.

The number of seismographs used in a CUS RAMP deployment will depend on a number of factors including: the magnitude and effects of the event that triggers the deployment, scientific and mitigation objectives, and the availability of funding, field personnel and instruments. Initial deployments will most likely use locally available analog and digital seismographs and perhaps the IRIS/PASSCAL RAMP instruments. If an extensive deployment is planned, additional seismographs (probably including some broadband instruments) will be available on relatively short notice (1-3 days) from IRIS/PASSCAL and university and government laboratories.

Because permanent networks of seismographs exist in the CUS, design and operation of a temporary RAMP deployment should consider both the locations of the network stations and availability of near-real-time data from network operators. A listing of these stations and their characteristics will be available from the ANSS-MA on-line database at http://folkworm.ceri.memphis.edu. It should be noted that potential damage to data links, instrumentation or network data centers may cause some network station data to be 
unavailable during a RAMP deployment. Because rapid response and locally available seismographs and other resources will be required for a CUS RAMP deployment, a list of available portable instrumentation and resources available in the CUS also will be available from the ANSS-MA on-line database.

\section{B. Personnel}

A list of names, addresses, and phone numbers of key personnel in the CUS and from other interested university, government or industry laboratories has been prepared and should be maintained. A list will be available from the ANSS-MA on-line database. Preevent planning of possible field operations and training exercises for key personnel is suggested because of the need for a rapid response of a CUS RAMP deployment. A member of the ANSS-MA post-earthquake response standing subcommittee, or their designate, will be responsible for keeping the response portion of the ANSS-MA GIS database and website up to date.

\section{Communications}

Rapid and effective RAMP field operations will require good communications among the RAMP participants and with emergency management teams and the media. Availability and distribution of field communications devices (e.g., cellular phones, two-way communications radios) will be coordinated through the Post-earthquake Technical Clearing House. RAMP activities also will be coordinated using post-earthquake Web tools set up by the USGS. The NEHRP Post-earthquake Investigations Plan also requires that a special website be established for communicating to the public, officials, etc. The RAMP Coordinator, together with the Data Coordinator, will be responsible for utilization of these field website tools and for seeing that appropriate information is posted on the special event NEHRP website. The RAMP Coordinator is also responsible for keeping the NEHRP 
Investigations Coordinator informed so that he/she may communicate information to the media.

\section{Transportation}

The use and availability of field vehicles, other than those belonging to RAMP participants, will be coordinated through the Post-earthquake Technical Clearing House. Use of aircraft for rapid deployment or data collection will be similarly coordinated. This will maximize efficiency in implementation of both scientific and emergency management operations.

\section{E. Logistics}

Potential logistical problems in a CUS RAMP deployment will depend on a large number of factors including: the size and scope of the deployment, the locations of array stations, the time of day of the triggering event (which will affect the speed of the response effort), the time of year of the triggering event (will affect weather, access and vegetation conditions), and degree of damage caused by the triggering event. In the event of a major earthquake that causes substantial damage, access to desirable field locations may be limited by emergency management, police or government decisions. In such a situation, it will be useful to provide RAMP field personnel with official letters or badges (from state geological surveys, emergency management personnel or state government offices) to facilitate access to restricted areas. Such materials will require pre-arrangement because of the need for rapid response for a RAMP deployment. Such arrangements are being made under the Post-earthquake Technical Clearing House plan being developed by the CUSEC Emergency Managers and State Geologists. 


\section{F. Coordination}

The RAMP field operations described herein are focused primarily on seismological data acquisition. In a post-major-earthquake situation, many other related field operations are likely to be conducted. These operations include: GPS/geodesy surveys; structural and geotechnical engineering studies, geological investigations, strong motion seismograph deployment (which could be part of the RAMP effort), rapid data management, integration and assessment efforts, and emergency management activities. Because RAMP implementation is part of the CUSEC Post-earthquake Technical Clearing House plan, this should guarantee that RAMP field operations are coordinated with these related activities.

\section{Post-RAMP Data Handling Procedures}

Past experiences of data collectors and distributors have taught us that planning for all stages of the data management process increases the likelihood of a final product that is the least costly, is of high quality, and is most useful to a large number of investigators. The guiding premise behind the policies and recommendations to follow is that data collected through a RAMP deployment should be assembled in a usable form and made openly available to all interested parties in a timely manner.

The recommendations fall into three areas of concern related to data management: 1) collection and quality assurance, 2) assembly and documentation, and 3) distribution and archive. The ANSS-MA post-earthquake response subcommittee will be responsible for addressing the recommendations in each of these areas and to work out the details. This subcommittee should work with the IRIS Data Management Center (DMC) to arrange for assistance with management and long-term archive of data collected through a CUS RAMP deployment. We also suggest that a test experiment be conducted to help potential RAMP participants anticipate problems. 


\section{A. Data Collection and Quality}

Data collection must be coordinated closely with the operations component of the RAMP effort to ensure a final product of high quality, usable data. It is anticipated from the list of equipment currently available for a RAMP deployment that a large number of different instrument types—analog and digital, antiquated and modern—can be anticipated. The final data product is to consist of data from as many of these disparate sources as possible. Because of the great diversity of instruments, it is particularly important to develop standardized forms (e.g., field sheets) to record instrument types, calibration, timing, positions, etc. It is recommended that the ANSS-MA post-earthquake response subcommittee develop such forms and make them available via the ANSS-MA website.

\section{B. Data Assembly and Documentation}

CUS RAMP participants should adopt a common data format to which all RAMP data will ultimately be converted and archived. To the extent possible, this format should be compatible with ANSS-MA processing and archival formats. It is recognized that data from a multi-institutional effort will be collected and analyzed in a wide variety of formats. However, the final data product should contain all the data in one format for ease of handling and archive. Each institution would be expected to submit its data in the adopted format. A large array of algorithms now exists for converting among formats and is available through the IRIS DMC. Identifying such algorithms would not only make the final assembly easier to effect, but would assist in the distribution to, and access by, those who prefer the data in a different format.

To ease the assembly process, a Data Coordinator for each RAMP deployment will be designated at the start of the collection effort to work with all participating institutions to assemble the final data product. He/she should either be a member of, or coordinate with the ANSS-MA post-earthquake response committee to insure compatibility with ANSS-MA permanent network data. The Data Coordinator will work with each institution to ensure 
that the data submitted for inclusion in the final product is not only in the adopted standard format but is accompanied by metadata, or the ancillary information necessary for its use by other researchers. While it is recognized that properly documented data sets require substantial effort to prepare, data without proper documentation are at best of limited value. For this reason, the coordinator will facilitate the assembly of the data documentation as well as of the data themselves, and funds should be identified for this effort as soon as possible in the experiment.

The concept of an integrated data product, which includes not only digital waveform data but as many related data sets as can be assembled, should be intimately woven into the plans for a RAMP deployment. This is discussed in the NEHRP Post-earthquake Investigations Plan, and relevant RAMP activities should be coordinated accordingly.

\section{Distribution and Archive}

Data collected in a RAMP deployment and assembled according to the above recommendations should be openly available to all interested researchers within a period of six months to one year. Because a CUS RAMP deployment is by its nature a temporary effort, we recommend that the data collected be held, distributed, and archived by an existing data center that can offer long-term data management. This should be the same management system employed by the ANSS-MA permanent networks, which is still in development. If this system is not the IRIS DMC, then we recommend that RAMP data also be archived at the IRIS DMC. IRIS policy currently requires that data collected with IRIS instruments be submitted to the DMC within a period of 6 months to one-year after the completion of the experiment. Anyone who participated directly or facilitated a RAMP experiment should have access to the data immediately after initial quality-control has been completed. This arrangement does not preclude other institutions from assembling and distributing their own data sets or products. A policy of timely distribution of RAMP data to all interested parties has important implications. It may impact the manner in which 
instruments are deployed and data are collected, and those not participating in the collection effort will greatly benefit from the efforts (and possibly the expense) of those that do (with credit given appropriately).

\section{Training and Long-term Continuation of a RAMP Plan}

The scope of this section is to outline a plan (or at least define the problem) to:

a) develop the ability to respond to a RAMP and

b) maintain that capability.

The regional Post-earthquake Technical Clearing House plan addresses the general issues of developing the capability to respond to a significant earthquake as well as maintaining it through regularly scheduled response exercises. These exercises should include RAMP components. This would facilitate development of technical deployment and operation procedures that interface effectively with other aspects of earthquake response (e.g., with emergency management efforts).

The concept of a full-scale RAMP deployment in the CUS has yet to be tested. Due to lack of practice, the seismological community is currently underprepared to respond to the next moderate, let alone large or devastating, earthquake in the CUS. As it may be years until the first full, and between subsequent, RAMP deployments regular exercising of a RAMP is of particular concern in the CUS. The basic approach for dealing with this is to institutionalize a continuous process of training that is:

a) comprehensive - involving as many aspects of a RAMP deployment as possible,

b) low cost,

c) productive - in particular minimizing lost time.

Since training all RAMP members on each type of recording instrument is impractical, a variety of training exercises should be considered. 
1) Hold training exercises centered on the IRIS/RAMP Reftek systems, which are state-of-the-art seismic recording instruments, and are a large share of the available digital recorders. While individuals could be trained at the IRIS Instrument Center at New Mexico Tech, it is more efficient to have a training exercise in the CUS. One example of this was a 2-day IRIS/RAMP sponsored instrument training exercise during September 18-23, 1995 held at The University of Memphis and attended by researchers from many CUS groups. Future exercises could be designed with dual purpose that includes some scientific objective (e.g. collection of site-response data) along with instrument training.

2) Institute the practice of inviting participants from a range of CUS institutions when responding to smaller earthquakes. Examples in which this has happened to a limited extent include the M4.5 earthquake near Ashtabula, Ohio in Jan. 2001, the Enola, Arkansas swarm that began in May, 2001 and the most recent M5 earthquake near Evansville, IN, in June, 2002

3) Regional planned PASSCAL experiments using either RAMP or IRIS broadband array instrumentation. Experiment PIs agree to invite as volunteers regional seismologists who are likely to be participants in a future RAMP deployment; this offers a low- to moderate-stress opportunity to deploy and operate instruments in a realistic environment.

4) At a minimum, each institution with potential to respond to an earthquake should be sure that its own personnel are trained to use the resources (hardware, software, etc.) they are likely to work with during a RAMP. 


\section{References}

Pavlis, G.L., A.J. Rudman, B.M. Pope, M.W. Hamburger, G.W. Bear, and H. AlShukri, Seismicity of the Wabash Valley seismic zone based on a temporary seismic array experiment, Seismo. Res. Letts., 73, 751-761, 2002.

Tuttle, M. P., E.S. Schweig, J.D. Sims, R.H. Lafferty, L.W. Wolf, M.L. Haynes, Marion L., The Earthquake Potential of the New Madrid Seismic Zone, Bull. Seismo.

Soc. Am., 92, 2080-2089, 2002.

\section{Appendix - Participants in the 1995 workshop:}

Geoff Abers

Haydar Al-Shukri

Chuck Ammon

Robert Bauer

Thomas M. Berg

James R. Blacklock

Lawrence W. Braile

Paul Bodin

Wang-Ping Chen

Jer-Ming Chiu

Timothy J. Clarke

Scott Davis

Tom Durham

Jim Fowler

Joan Gomberg

Michael W. Hamburger

Robert Herrmann

Norman Hester

David Hoffman

Steve Horton

Doug Johnson

Arch Johnston

John D. Kiefer

Cragin Knox

Timothy Long

Edward T. Luther

Jeff Munsey

Gary Pavlis

Eugene Schweig

John L. Sexton

Bob Smalley

Don Steeples

Seth Stein

Richard T. Williams

Doug Wiens

James H. Williams

Norman F. Williams

Lorraine Wolf

Michael E. Wysession 